\title{
On the Detection of Induction-Motor Rotor Fault by the Combined "Time Synchronous Averaging-Discrete Wavelet Transform" Approach
}

\begin{abstract}
Nabil Ngote ${ }^{\dagger}$, Mohammed Ouassaid*, Saïd Guedira** and Mohamed Cherkaoui***
Abstract - Induction motors are widely used in industrial processes since they offer a very high degree of reliability. But like any other machine, they are vulnerable to faults, which if left unmonitored, might lead to an unexpected interruption at the industrial plant. Therefore, the condition monitoring of the induction motors have been a challenging topic for many electrical machine researchers. Indeed, the effectiveness of the fault diagnosis and prognosis techniques depends very much on the quality of the fault features selection. However, in induction-motor drives, rotor defects are the most complex in terms of detection since they interact with the supply frequency within a restricted band around this frequency, especially in the no-loaded case. To overcome this drawback, this paper deals with an efficient and new method to diagnose the induction-motor rotor fault based on the digital implementation of the monitoring algorithm based on the association of the Time Synchronous Averaging technique and Discrete Wavelet Transform. Experimental results are presented in order to show the effectiveness of the proposed method. The obtained results are largely satisfactory, indicating a promising industrial application of the combined "Time Synchronous Averaging - Discrete Wavelet Transform" approach.
\end{abstract}

Keywords: Condition monitoring, Fault diagnosis, Discrete Wavelet Transform (DWT), Induction motors, Signal processing algorithms, Time Synchronous Averaging (TSA)

\section{Introduction}

Nowadays, induction motors are the most important rotating electric machines within industrial applications. This is mainly due to their robustness, low cost, efficiency, and reliability.

However, in the practical applications, induction motors are subjected to electrical, environmental, mechanical and/or thermal stresses, which create failures in different parts of these machines [1]. Interruptions can be caused by rotor faults, stator faults, rotor-stator eccentricity, and bearing failures [1].

Therefore, a permanent condition monitoring of the induction machine is of high interest since it contributes to minimizing the downtime and improves its reliability and availability. Early diagnosis of these faults is an extensively investigated field for cost and maintenance time savings [2].

Traditionally, several diagnosis techniques were used to

$\dagger$ Corresponding Author: Dept. of Electromechanical Engineering, Ecole Nationale Supérieure des Mines de Rabat, Rabat, Morocco. (ngotenabil@gmail.com)

* Dept. of Electrical Engineering, Ecole Mohammedia d'Ingénieurs, Rabat, Morocco. (ouasaid@yahoo.fr)

** Dept. of Electromechanical Engineering, Ecole Nationale Supérieure des Mines de Rabat, Rabat, Morocco (guedirasaid@gmail.com)

*** Dept. of Electrical Engineering, Ecole Mohammedia d'Ingénieurs, Rabat, Morocco. (cherkaoui@emi.ac.ma)

Received: July 2, 2014; Accepted: July 11, 2015 supervise the induction motor faults, such as temperature measurements, infrared recognition, radio frequency emissions, noise monitoring, vibration measurement, speed fluctuations or torque sensing [3-5]. But the major problem of these methods is that they require direct access to the machine in order to place transducers for the monitoring.

To overcome this drawback, intensive research efforts have recently focused on electrical monitoring methods, which use only non-invasive sensors (i.e. current sensors) [6].

Furthermore, it is known that an important factor of motor condition monitoring and fault diagnosis is how to extract the features of motor signals. From this perspective, three approaches have been developed by researchers:

1- Time-domain analysis: It is the simplest form of signal processing, since the signal magnitude is examined in the time domain [7].

2- Frequency-domain analysis: It is widely adopted for condition monitoring and fault diagnosis of electrical motors. The most common frequency-domain analysis technique is the so-called Motor Current Signature Analysis (MCSA). MCSA focuses on the spectral analysis of the stator current and has been successfully used in the diagnosis of induction-motor faults. The advantage of MCSA is that it needs only one current sensor and is based on straightforward signal-processing techniques such as Fast Fourier Transforms [8-9]. 
3-Time-frequency domain analysis: It consists of the time, frequency representation of a signal, which is inherently suited to indicate transient events in the signal. The most popular time-frequency domain analysis is the wavelet technique. Wavelet techniques for fault monitoring and diagnosis of induction motor are increasing, indeed, because they can be used for a localized analysis in a time-frequency or time-scale domain. It is thus a powerful tool for condition monitoring and fault diagnosis. In this regard, intensive research efforts have focused on the use of approximation and detail signals for extracting the contribution of fault frequency components [10-18].

Among the various induction motor defects, rotor faults are the most important, since the cumulative effect may lead to a major motor malfunction. Diagnosis of rotor failures has long been an important but complicated task in the area of induction motor condition monitoring. Indeed, especially at light load, it is difficult to distinguish between healthy and faulty rotors, as the rotor-defect characteristic frequencies are very close to the fundamental component and their amplitudes are small in comparison [19-20].

To alleviate this drawback, a method exploiting the cyclostationarity of electrical signals is developed for the motor condition monitoring. The "cyclostationarity" term was introduced by Bennett in 1958 [21] and the theory of cyclostationarity was developed by Gardner [22]. More recently, Bonnardot et al. have shown that this theory can bring new solutions to fault detection and diagnosis problems [23]. Indeed, in the case of the cyclostationary signal, each period (or cycle) is considered as the same random process realization. Therefore, if these cycles are superposed, the overall average can be calculated: this average is also called Time Synchronous Average. Time Synchronous Averaging(TSA) is a method developed by McFadden in 1987; it allows the extraction of a deterministic component from a signal. TSA consists of averaging together a series of signal segments each corresponding to one period of a synchronizing signal [24].

Nowadays, very little work has been done to exploit the electrical-signal cyclostationary characteristics in order to diagnose induction motor rotor fault. An approach associating TSA and a time-domain analysis was developed [25] and a combination of TSA with a frequency-domain analysis was depicted [26].

This paper proposes a technique combining the TSA to a time-frequency domain analysis, based on the following steps:

1. Determination of the stator current TSA;

2. Residual current calculation by subtraction between the stator current and its TSA;

3. Application of DWT to the residual current in order to diagnose the induction-motor rotor fault.
The main novelty of this article stems from the introduction of the notion of "combined TSA - DWT approach" in order to detect induction-motor drive faults, even in the non-loaded case.

The rest of this paper is organized as follows. Section 2 depicts the architecture of the combined "Time Synchronous Averaging - Discrete Wavelet Transform" approach. Section 3 is devoted to the detailed description of the experiment. The comparison results and discussion are presented in Section 4. Finally, conclusions are mentioned in Section 5.

\section{Architecture of the Combined "TSA - DWT" Approach}

\subsection{Time Synchronous Averaging (TSA)}

The asynchronous motor operating process and the electric supply fluctuations cause the non-stationary behavior of the stator current signal.

The idea is to exploit the electrical-signal cyclostationary characteristics in order to identify the faults which occur in an asynchronous-motor drive. Therefore, in this work, the first-order cyclostationarity of stator current and voltage is largely exploited.

Furthermore, a rotor fault can be detected by highlighting a stator-current amplitude or phase modulation. However, the modulated-signal weak frequency band makes it too difficult to detect modulation. An alternative to overcome this difficulty is proposed by MacFadden [24]: the Time Synchronous Averaging (TSA) method. It's a way to reshape the signal before its processing.

The $T$-period TSA of a signal $s(t)$ is defined as follows:

$$
\langle s(t)\rangle_{T}=\lim _{K \rightarrow+\infty} \frac{1}{K} \sum_{k=0}^{K-1} s(t+k \cdot T)
$$

The TSA method consists of averaging $s(t)$-signal shifted versions of a whole number of $T$ periods.

This method allows the separation between the excitation sources and, consequently, fault identification. Indeed, consider a signal $s(t)$ sum of $T_{1}$-period signal $s_{1}(t), T_{2^{-}}$ period signal $s_{2}(t)$ and noise. The application of the TSA method to $s(t)$, at respectively $T_{1}$ and $T_{2}$ period allows the separation between $s_{I}(t)$ and $s_{2}(t)$. In fact, we can prove that:

$$
\begin{aligned}
& \langle s(t)\rangle_{T_{1}}=s_{1}(t) \\
& \langle s(t)\rangle_{T_{2}}=s_{2}(t)
\end{aligned}
$$

By applying a similar approach, the stator current can be decomposed as follows: 


$$
I_{s}(t)=I_{s_{h}}(t)+I_{s_{\text {mec }}}(t)+n(t)
$$

where $I_{\text {sh }}(t), I_{\text {smec }}(t)$ and $n(t)$ are respectively the harmonic stator-current harmonic component, the mechanicalstructure-related stator current and the noise.

In fact, the asynchronous motor monitoring consists of supervising the signal harmonic part. So, harmonic frequency $(50 \mathrm{~Hz})$ which is related to electrical phenomena and mechanical-structure-related frequency must be separated.

For this purpose, the TSA method will be applied to the stator current. The $T_{h}$-period TSA of stator current is done by the following relation, as established in (2) and (3):

$$
\left\langle I_{s}(t)\right\rangle_{T_{h}}=\lim _{K \rightarrow+\infty} \frac{1}{K} \sum_{k=0}^{K-1} I_{s}\left(t+k \cdot T_{h}\right)=I_{s_{h}}(t)
$$

where $T_{h}=1 / f_{s}$ is the harmonic period and $f_{s}=50 \mathrm{~Hz}$ the harmonic frequency corresponding to supply frequency.

Note that only the harmonic part of the stator current $I_{s h}(t)$ corresponding to $50 \mathrm{~Hz}$ frequency remains in the averaged signal. Thus, the synchronous averaging allows an effective separation between electrical-related and mechanical-related components. The subtraction between the stator current and its TSA gives the residual current where only mechanical-related frequencies remain, as shown in (5):

$$
I_{r e s}(t)=I_{s}-\left\langle I_{s}\right\rangle_{T_{h}}
$$

It's a very interesting property that will allow conditioning a mechanical-structure-related indicator monitoring an eventual rotor fault.

\subsection{Discrete Wavelet Transform (DWT)}

For many years, Fourier Transform has been used for signal processing, since it is suitable for the study of a wide range of signals. The Fourier analysis consists in decomposing a signal into sine waves with different frequencies. Similarly, a wavelet analysis is the decomposition of a signal into shifted and scaled versions of a function called the 'mother wavelet'.
There are two types of wavelet, the continuous wavelet transform (CWT) and discrete wavelet transform (DWT).

The CWT is the sum over time of the signal multiplied by scaled and shifted versions of the wavelet, as shown in (6).

$$
C(a, b)=\frac{1}{\sqrt{a}} \int_{-\infty}^{+\infty} s(t) \cdot \psi\left(\frac{t-b}{a}\right) \cdot d t
$$

where $s(t)$ is the signal, $a$ and $b$ being real called dilation and translation parameters respectively and $\psi$ is the wavelet function.

The DWT consists in sampling the scaling and shifted parameters. This leads to high-frequency resolution at low frequencies and high-time resolution for higher frequencies.

The DWT is preferred in the industry due to its less computational complexity and less computational time compared to CWT [27].

DWT decomposes a signal by passing it successively through high-pass and low-pass filters into its approximate and detailed versions using Multi-Resolution Analysis (MRA), and this is called the Mallat Algorithm as shown in Fig. 1. [27].

The original signal is denoted by $s(t)$, with a sampling rate of $f$ samples/sec. The low-pass filter is denoted by LPF while the high-pass filter is denoted by HPF.

The first level of decomposition coefficients are $a_{1}$ and $d_{1}$, where $a_{1}$ is the approximate version of the original signal and $d_{1}$ is the detailed version of the original signal. Further decomposition of $a_{1}$ gives $a_{2}$ and $d_{2}$ and so on. At each level, the HPF produces the detail coefficients $\left(d_{j}\right)$, while the LPF produces the approximation coefficients $\left(a_{j}\right)$.

Finally, the signal $s(t)$ can be approximated using the DWT by [27]:

$$
\begin{aligned}
s(t) & =\sum_{i} \alpha_{i}^{n} \varphi_{i}^{n}(t)+\sum_{j=1}^{n} \sum_{i} \beta_{i}^{j} \psi_{i}^{j}(t) \\
& =a_{n}+d_{n}+\ldots . .+d_{1}
\end{aligned}
$$

where $\alpha_{i}^{n}, \beta_{i}^{j}$ are respectively, the scaling and the wavelet coefficients, $\phi^{n}(t), \psi^{\dagger}(t)$ are respectively the scaling function at level $n$ and the wavelet function at level $j, n$ is the decomposition level, $a_{n}$ is the approximation signal at

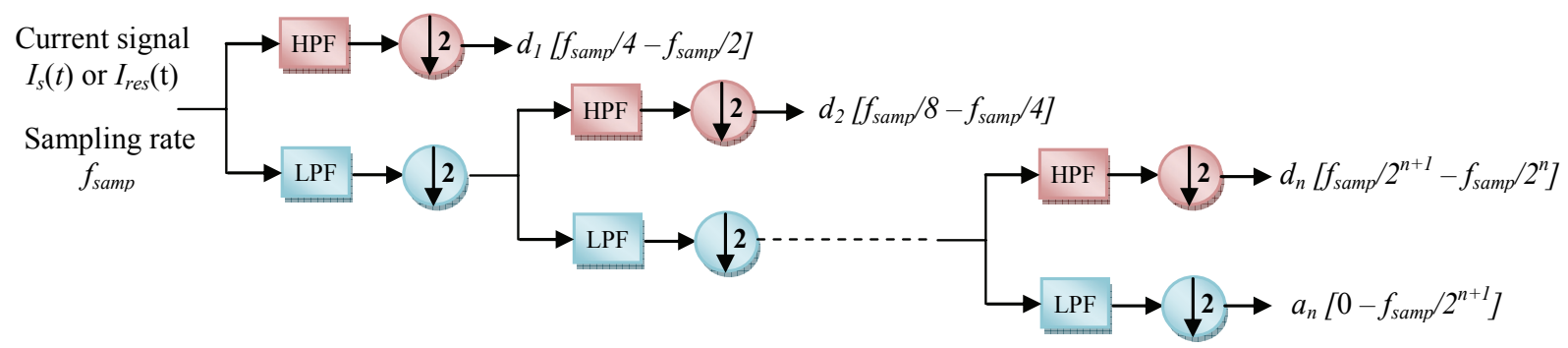

Fig. 1. The Mallat algorithm applied to stator or residual current 
level $n$ and $d_{j}$ is the detail signal at level $j$. [27].

In accordance with Nyquist rule, a down-sampling by two for successive levels, halves the samples number of the previous level, with no information losses. If $f$ (samples/sec) is the sampling rate used for capturing $s(t)$, the detail $d_{j}$ contains the information concerning the signal components whose frequencies are included in the interval $\left[f / 2^{j+1}, f / 2^{j}\right]$. The approximation signal $a_{n}$ includes the low frequency components of the signal, belonging to the interval $\left[0, f / 2^{n+1}\right]$.

The high frequency band extends from half to full Nyquist frequency, where Nyquist frequency is given as $f / 2$.

\section{Detailed Description of the Experiment}

\subsection{Experimental setup}

The testing ground used includes an industrial threephase induction motor of $400 \mathrm{~V}, 6.2 \mathrm{~A}, 50 \mathrm{~Hz}, 3 \mathrm{~kW}, 1385$ rpm. The data acquisition system (DAQ) has a resolution of 24-bit, with $128 \mathrm{MB}$ of memory and the processor speed is $600 \mathrm{MHz}$. The sampling rate taken is $f_{\text {samp }}=25.6 \mathrm{kHz}$, so the number of samples per average cycle of $50 \mathrm{~Hz}$ is $N_{\text {samp }}=512(25600 / 50=512)$.

Supply voltage is measured by means of a voltage transducer (Voltage LEM) while stator current is measured by means of a current transducer (Current LEM). The velocity is measured with an optical tachometer. The block diagram of Fig. 2 shows the implementation technique adopted during experimental testing.

The tests are first performed for the no-loaded motor, in healthy and defective cases respectively. The same tests are carried out with the half-nominal loaded motor.

Indeed, under healthy operating conditions, the balanced three-phase supply current system creates a forward rotating magnetic field, which rotates at synchronous speed. This air-gap field induces currents in the rotor with a frequency proportional to the rotor slip $s$, and these currents generate a forward rotating field. So, for a symmetrical motor (healthy machine), there is not any backward field in the air-gap [28].

But, when a rotor failure occurs an electrical imbalance

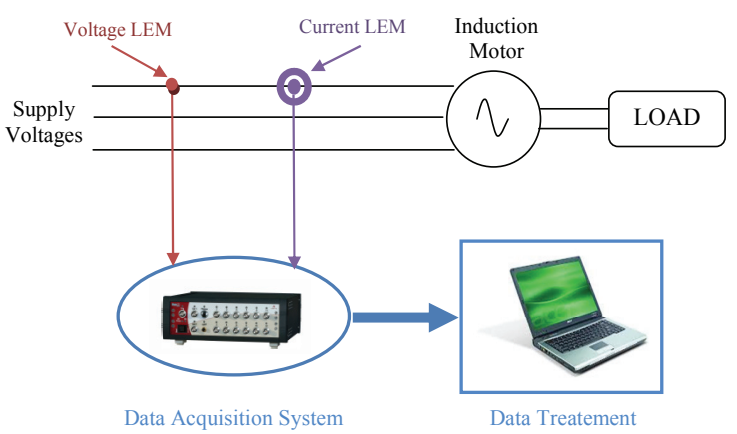

Fig. 2. Block Diagram of the implemented experimental device appears, since the rotor resistance values of the three phases are no longer equal to each other [29].

Therefore, under rotor faults, an asymmetry appears in the rotor circuit and an additional backward field is produced by the imbalanced rotor currents [30, 31].

Note that the main effect of the rotor fault is the amplitude modulation of the stator current. It is characterized by the upper and lower sidebands. The formula used to calculate the components is given by [31]:

$$
f_{\text {defect }}=(1 \pm 2 s) \cdot f_{s}
$$

where $f_{s}$ is the electrical supply frequency and $s$ the per unit slip.

\subsection{Selection of DWT decomposition level}

A suitable number of decomposition levels depends on the sampling frequency $f_{\text {samp }}$. It has to be chosen in order to allow the high-level signals (approximation and details) to cover all the range of frequencies along which the sideband is localized.

Otherwise, several types of mother wavelets exist and have different properties. However, due to the well-known properties of the orthogonal Daubechies family [32], a mother wavelet of this family will be used in this paper.

Thereby, the DWT is carried out decomposing the current signal into 10 levels, each one of them having its own detailed coefficients and a determined range of frequencies, as shown in Table 1. The DWT is done using the Daubechies 5 (db5) wavelet with 10 decomposition levels [33].

Table 1. Frequency bands at different decomposition levels

\begin{tabular}{c|c}
\hline Decomposition Level & Frequency Range $(\mathrm{Hz})$ \\
\hline Detail d1 & $12800-6400$ \\
\hline Detail d2 & $6400-3200$ \\
\hline Detail d3 & $3200-1600$ \\
\hline Detail d4 & $1600-800$ \\
\hline Detail d5 & $800-400$ \\
\hline Detail d6 & $400-200$ \\
\hline Detail d7 & $200-100$ \\
\hline Detail d8 & $100-50$ \\
\hline Detail d9 & $50-25$ \\
\hline Detail d10 & $25-12.5$ \\
\hline Approximate a10 & $12.5-0$ \\
\hline
\end{tabular}

\subsection{Signal synchronization}

During the acquisition of voltage signal, a problem of cycle drift from one electric cycle to another appears; it's due to the electrical supply fluctuations. The cyclic statistic rules cannot be directly applied to these signals to extract desired information, except if a way to compensate these fluctuations is proposed.

A preliminary stage is needed: the current and voltage 
signals must be re-sampled according to a reference which "follows" these fluctuations: it's "the synchronization of the current and voltage signals". The purpose is to synchronize all electric cycles according to the same reference, so all cycles must be superimposed after the synchronization process. In this perspective, a re-sampling algorithm that allows electrical signals synchronization is developed, as illustrated in Fig. 3.

The voltage signal $V$ is first cut out in slices, each one corresponding to one period $(T=20 \mathrm{~ms})$, and each period containing an integer number of samples $N_{\text {samp }}$.

In this paper:

- The acquisition duration $T_{a}$ is 20 seconds, so the number of voltage slices is $N=T_{a} / T=1000$;

- The sample rate is $25.6 \mathrm{kHz}$, so $N_{\text {samp }}=512$ samples per period $(512=25.6 \mathrm{kHz} \times 20 \mathrm{~ms})$.

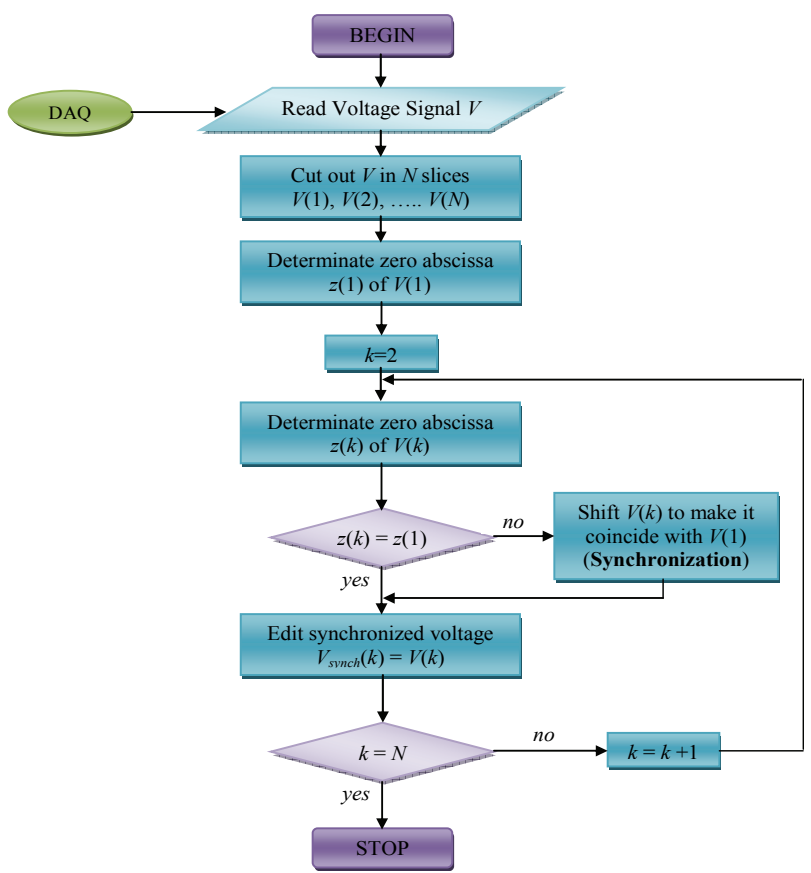

Fig. 3. Signal synchronization algorithm

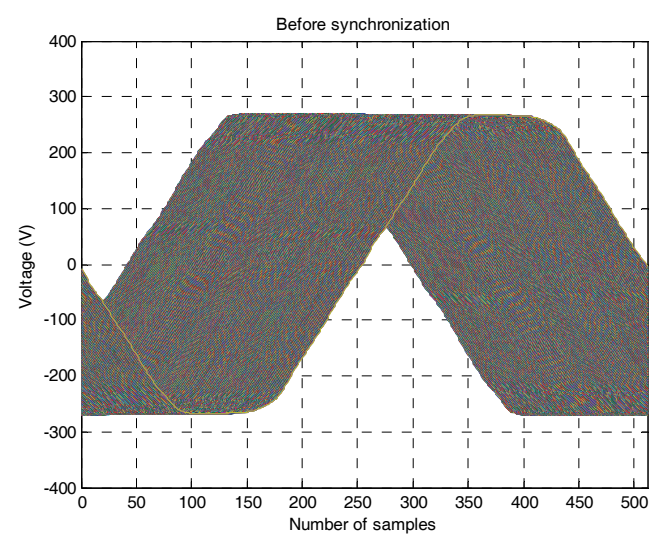

Fig. 4. Superposition of 1000 voltage cycles before synchronization

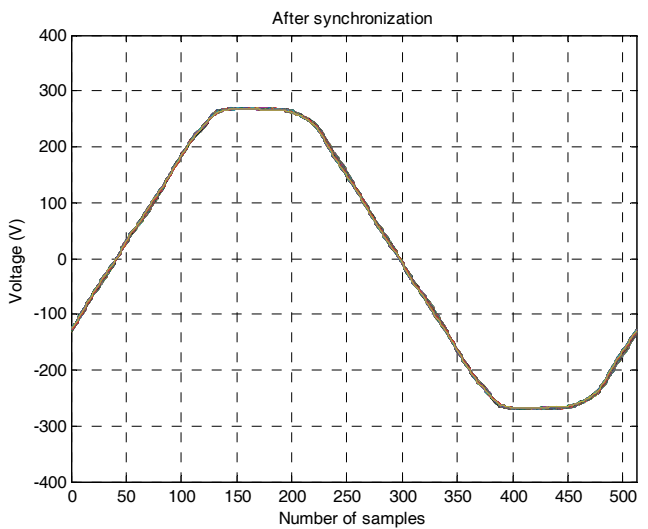

Fig. 5. Superposition of 1000 voltage cycles after synchronization

The shift between the first voltage period, taken as a reference, and the others are estimated: for this purpose, the first-period zero abscissa and the $\mathrm{k}^{\text {th }}$-period zero abscissa (for $\mathrm{k}=2$ to $\mathrm{N}$ ) are determined; the shift corresponds to the difference between these two abscissas. Then, each period is shifted to make it coincide with the first one (reference). If the two periods are already synchronous, the shift is then null.

The voltage signals before and after synchronization are represented in Fig. 4 and Fig. 5 respectively.

Once all cycles are synchronized, the signal is rebuilt by setting these cycles end to end. All cycles are now synchronous and the TSA can be carried out.

\section{Comparison Results and Discussion}

\subsection{No-loaded motor case}

The DWT of the stator current $I_{s}$ is applied in first. Fig. 6 and Fig. 7 show the stator current signal $\left(I_{s}\right)$ and the upper-

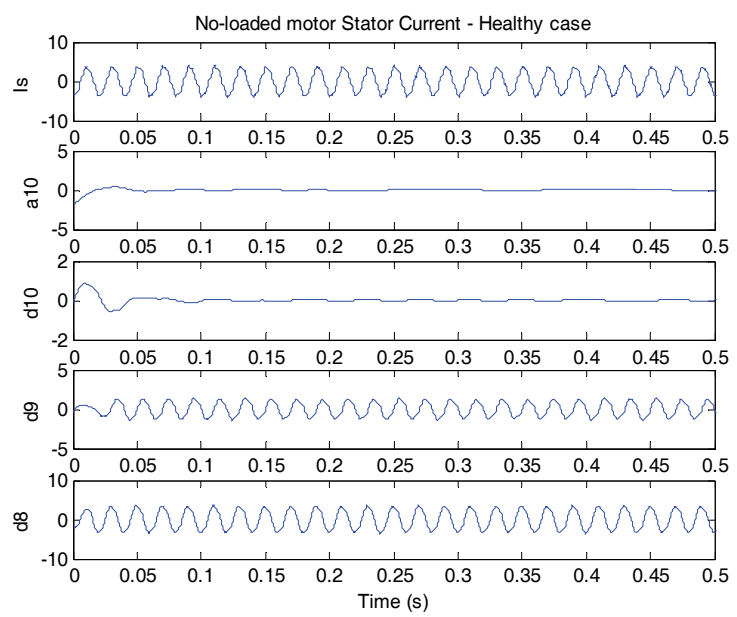

Fig. 6. High-level wavelet signals results from the DWT signal analysis of stator current in healthy case at no-load 


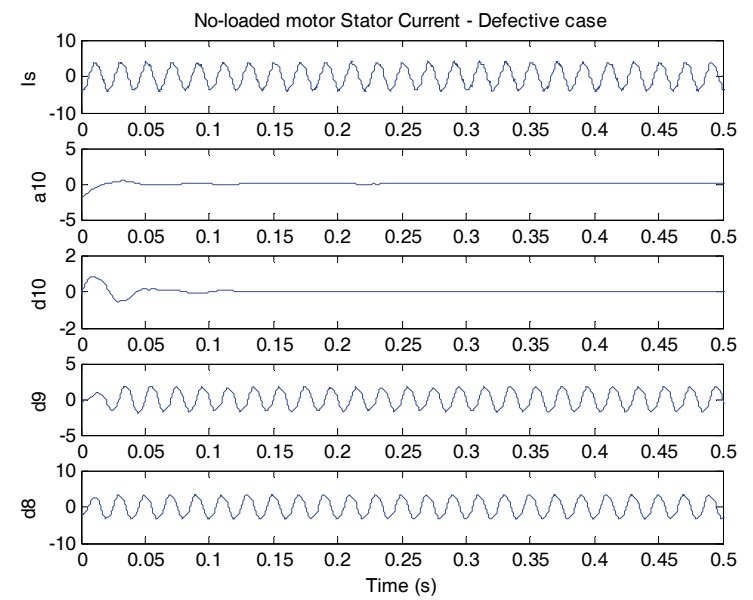

Fig. 7. High-level wavelet signals results from the DWT signal analysis of stator current in defective cases at no-load

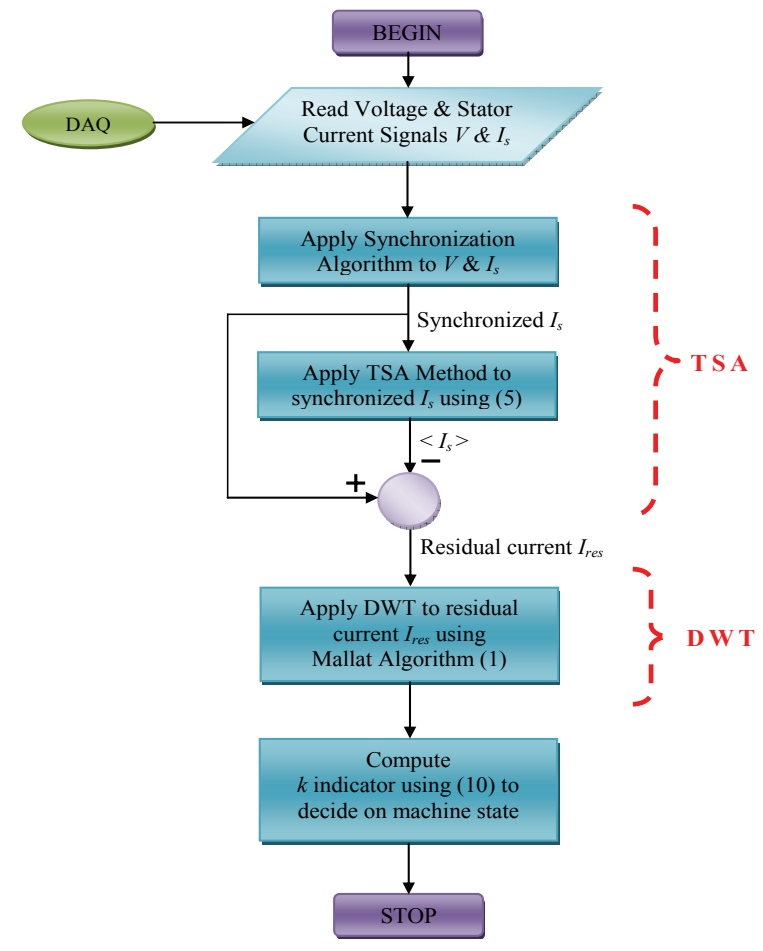

Fig. 8. Flowchart of the proposed hybrid "TSA-DWT" rotor-faults detection algorithm

level signals $a_{10}, d_{10}, d_{9}$ and $d_{8}$, for the healthy and faulty cases respectively.

The comparison between the plots of DWT in the healthy and faulty case does not allow detecting the rotor fault.

So, the idea is to combine the TSA method and DWT in order to diagnose the induction-motor rotor fault, as proposed by the algorithm of Fig. 8 .

The DWT is now applied to the residual current $I_{\text {res }}$. Fig. 9 and Fig. 10 show the residual current signal $\left(I_{\text {res }}\right)$ and the upper-level signals $a_{10}, d_{10}, d_{9}$ and $d_{8}$, for the healthy and faulty cases respectively.

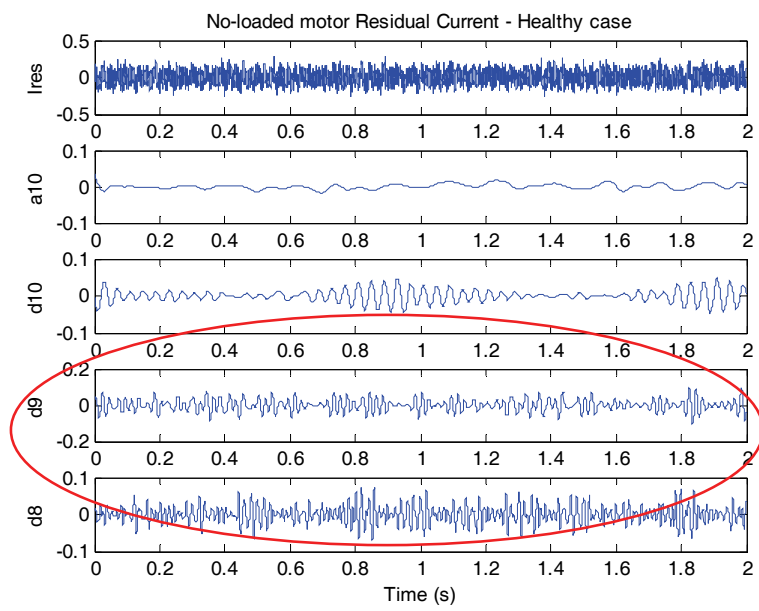

Fig. 9. High-level wavelet signals result from the DWT signal analysis of residual current in healthy case at no load

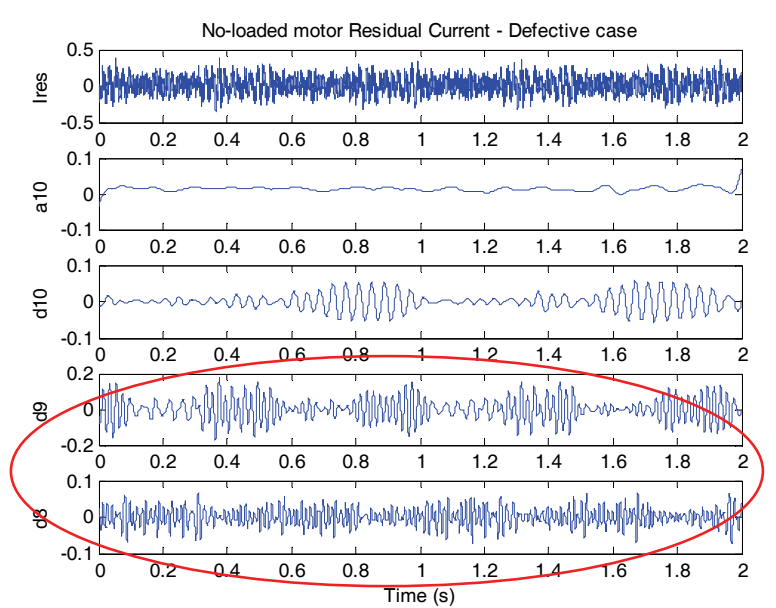

Fig. 10. High-level wavelet signals results from the DWT signal analysis of residual current in defective case at no load

The difference between the $9^{\text {th }}$ detail-level plots of residual current, in healthy and defective cases, is very clear. So, the DWT applied to residual current allows the detection of rotor fault.

\subsection{Half-nominal loaded motor test}

Fig. 11 and Fig. 12 show the stator-current signal $\left(I_{s}\right)$ and the upper-level signals $a_{10}, d_{10}, d_{9}$ and $d_{8}$, for the healthy and faulty cases respectively.

The comparison between the plots of DWT in the healthy and faulty case does not allow detecting easily the rotor fault. The $9^{\text {th }}$ detail-level plot shows a little difference between the two cases, but this difference is too small to be significant.

So, the idea is to apply the DWT to the residual current $I_{\text {res. }}$. Fig. 13 and Fig. 14 show the residual current signal $\left(I_{\text {res }}\right)$ and the upper-level signals $a_{10}, d_{10}, d_{9}$ and $d_{8}$, for the healthy and faulty cases respectively. 


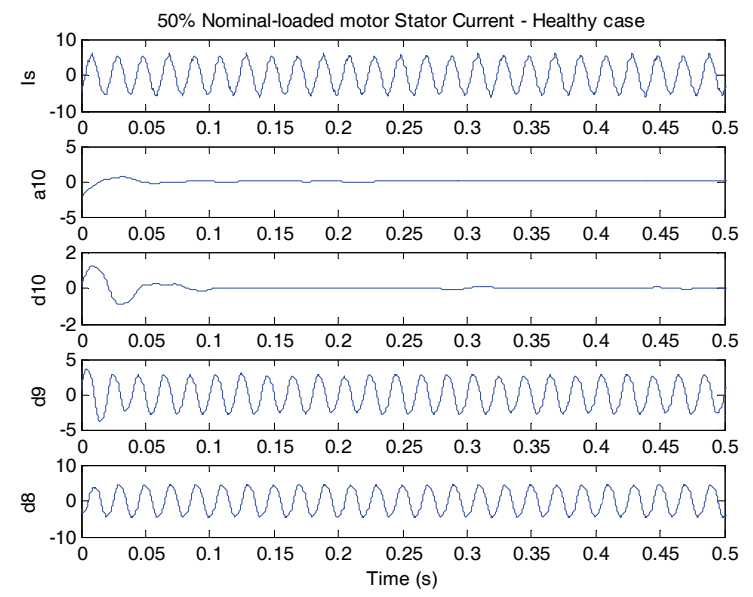

Fig. 11. High-level wavelet signals result from the DWT signal analysis of stator current in healthy case with a $50 \%$ nominal load

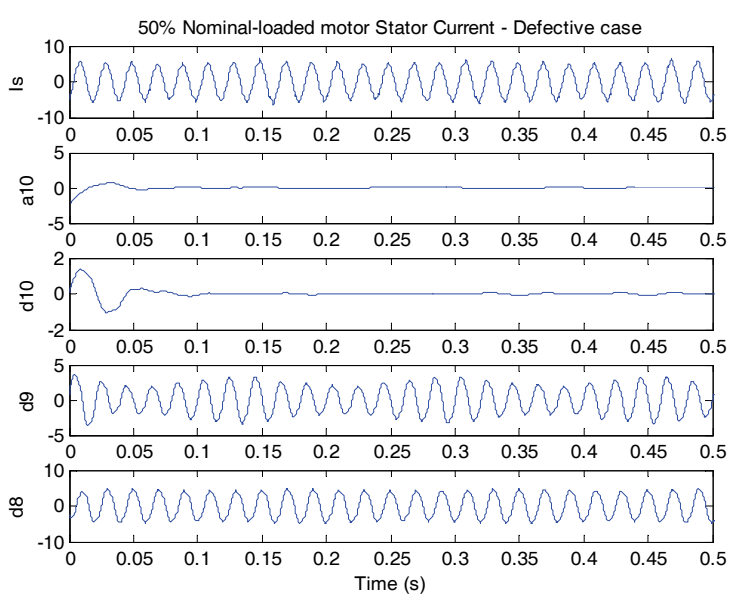

Fig. 12. High-level wavelet signals result from the DWT signal analysis of stator current in defective case with a $50 \%$ nominal load

The difference between the $8^{\text {th }}$ and $9^{\text {th }}$ detail-level plots of residual current, in healthy and defective cases, is very clear. So, the DWT applied to residual current allows the detection of rotor fault.

\subsection{Discussion}

To show the effectiveness of the proposed approach, the signal will be conditioned in order to develop an inductionmotor diagnosing indicator. For this purpose, the energy concentrated in each detail level of wavelet decomposition will be calculated, for both the healthy and defective cases.

The detail energy at level $j$ is given by:

$$
E_{j}=\sum_{n=1}^{N}\left|d_{j}(n)\right|^{2}
$$

where $j$ is the level of detail, $d_{j}$ is the detail signal at level $j$

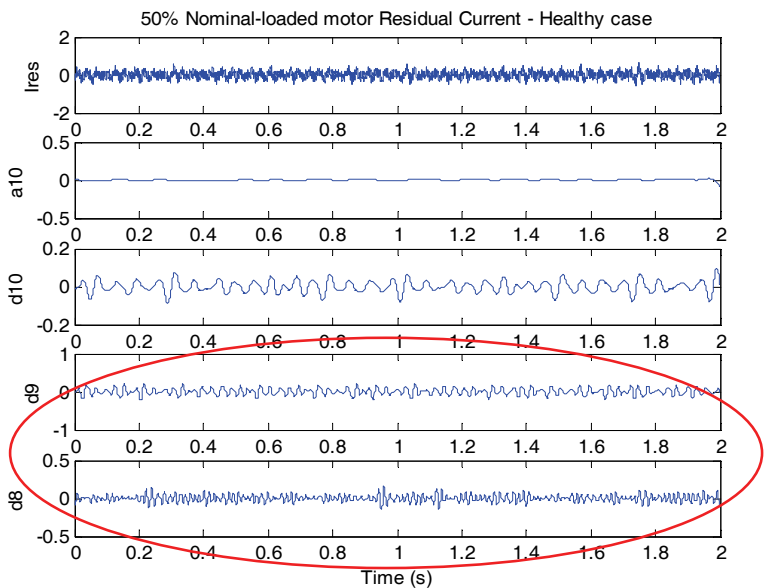

Fig. 13. High-level wavelet signals result from the DWT signal analysis of residual current in healthy case with a $50 \%$ nominal load

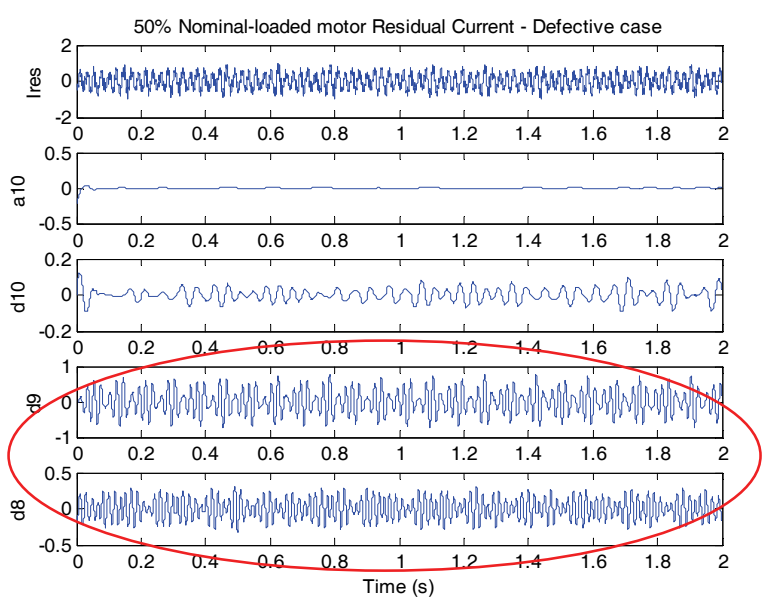

Fig. 14. High-level wavelet signals result from the DWT signal analysis of residual current in defective case with a $50 \%$ nominal load

and $N$ is the total number of samples in the signal. In this paper, the observation time is 2 seconds, so $N=512000(N$ $=2 \mathrm{~s} \mathrm{x} 25.6 \mathrm{kHz}$ ).

Detail energy of stator current signal is calculated using (9) up to level 10, for the healthy and defective cases and the results are given in Table 2 (Total Energy).

Table 2. Total Energies at different decomposition levels

\begin{tabular}{c|c|c|c|c}
\hline \multirow{2}{*}{ Level } & \multicolumn{2}{|c|}{ No-loaded motor } & \multicolumn{2}{c}{ Motor with a 50\% nominal load } \\
\cline { 2 - 5 } & $\begin{array}{c}E_{j} \text { (Joules) } \\
\text { healthy case }\end{array}$ & $\begin{array}{c}E_{j} \text { (Joules) } \\
\text { faulty case }\end{array}$ & $\begin{array}{c}E_{j} \text { (Joules) } \\
\text { healthy case }\end{array}$ & $\begin{array}{c}E_{j} \text { (Joules) } \\
\text { faulty case }\end{array}$ \\
\hline $\mathrm{d} 1$ & 10 & 10 & 10 & 10 \\
\hline $\mathrm{d} 2$ & 5 & 5 & 0 & 0 \\
\hline $\mathrm{d} 3$ & 10 & 10 & 10 & 10 \\
\hline $\mathrm{d} 4$ & 20 & 30 & 30 & 30 \\
\hline $\mathrm{d} 5$ & 200 & 170 & 310 & 310 \\
\hline $\mathrm{d} 6$ & 1920 & 2020 & 2770 & 2730 \\
\hline $\mathrm{d} 7$ & 1540 & 1840 & 2820 & 2750 \\
\hline $\mathrm{d} 8$ & $2.549 \mathrm{e}+5$ & $2.367 \mathrm{e}+5$ & $5.227 \mathrm{e}+5$ & $5.159 \mathrm{e}+5$ \\
\hline $\mathrm{d} 9$ & $8.141 \mathrm{e}+4$ & $1.178 \mathrm{e}+5$ & $1.915 \mathrm{e}+5$ & $1.799 \mathrm{e}+5$ \\
\hline $\mathrm{d} 10$ & 770 & 690 & 1910 & 2060 \\
\hline
\end{tabular}


The corresponding graphs are shown in Fig. 15 below.

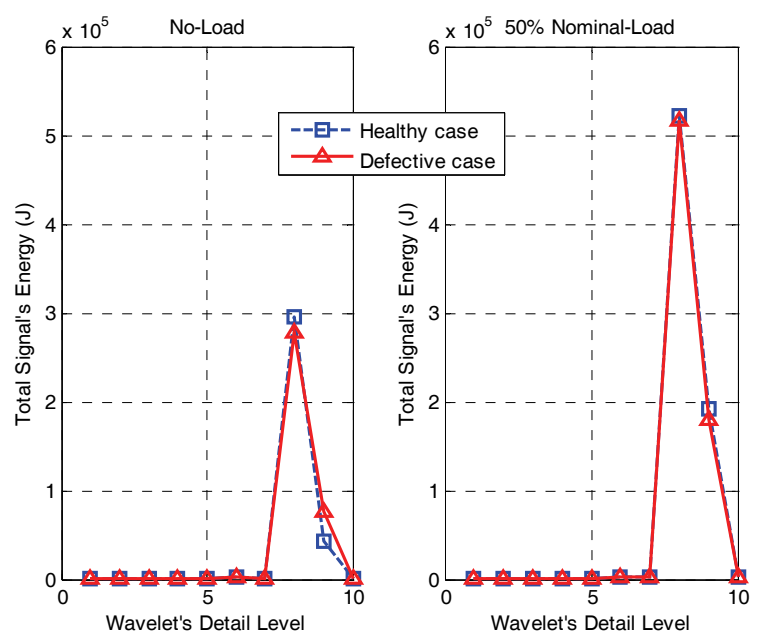

Fig. 15. Total energy corresponding to stator current in healthy and faulty cases at no load and with a $50 \%$ nominal load

From this experiment, it is observed that the total energy consumption in the faulty case is nearly the same as in the healthy case, since the two curves are quasi combined, as shown in Fig. 15.

It is also noted that the $8^{\text {th }}$ level-total-energy value is the highest. This can be explained by the predominance of the fundamental component $(50 \mathrm{~Hz})$ at this level, since the frequency range associated to this level is 100 to $50 \mathrm{~Hz}$, as shown in Table 2.

Therefore, the diagnosis of rotor fault by this method is impossible: the total energy cannot be considered as a sensitive indicator of rotor fault.

To overcome the above inconvenience, the same procedure will be followed for the residual current, obtained by subtraction between the stator current and its TSA.

Detail energy of residual current signal is calculated for the healthy and defective cases and the results are given in Table 3 (Residual Energy).

Table 3. Residual Energies at different decomposition levels

\begin{tabular}{c|c|c|c|c}
\hline \multirow{2}{*}{ Level } & \multicolumn{2}{|c|}{ No-loaded motor } & \multicolumn{2}{c}{ Motor with a 50\% nominal load } \\
\cline { 2 - 5 } & $\begin{array}{c}E_{j} \text { (Joules) } \\
\text { healthy case }\end{array}$ & $\begin{array}{c}E_{j} \text { (Joules) } \\
\text { faulty case }\end{array}$ & $\begin{array}{c}E_{j} \text { (Joules) } \\
\text { healthy case }\end{array}$ & $\begin{array}{c}E_{j} \text { (Joules) } \\
\text { faulty case }\end{array}$ \\
\hline $\mathrm{d} 1$ & 6.794 & 6.98 & 7.302 & 9.500 \\
\hline $\mathrm{d} 2$ & 2.856 & 3.13 & 3.183 & 4.900 \\
\hline $\mathrm{d} 3$ & 10.59 & 11.41 & 8.075 & 12.60 \\
\hline $\mathrm{d} 4$ & 20.06 & 21.23 & 26.82 & 36.10 \\
\hline $\mathrm{d} 5$ & 77.58 & 85.05 & 157.8 & 162.7 \\
\hline $\mathrm{d} 6$ & 75.05 & 86.57 & 410.0 & 412.9 \\
\hline $\mathrm{d} 7$ & 7.549 & 11.02 & 64.09 & 74.20 \\
\hline $\mathrm{d} 8$ & 27.38 & 27.99 & 104.7 & 1008 \\
\hline $\mathrm{d} 9$ & 55.21 & 185.2 & 430.3 & 5771 \\
\hline $\mathrm{d} 10$ & 13.96 & 23.51 & 49.36 & 67.70 \\
\hline
\end{tabular}

The corresponding graphs are shown in Fig. 16 below.

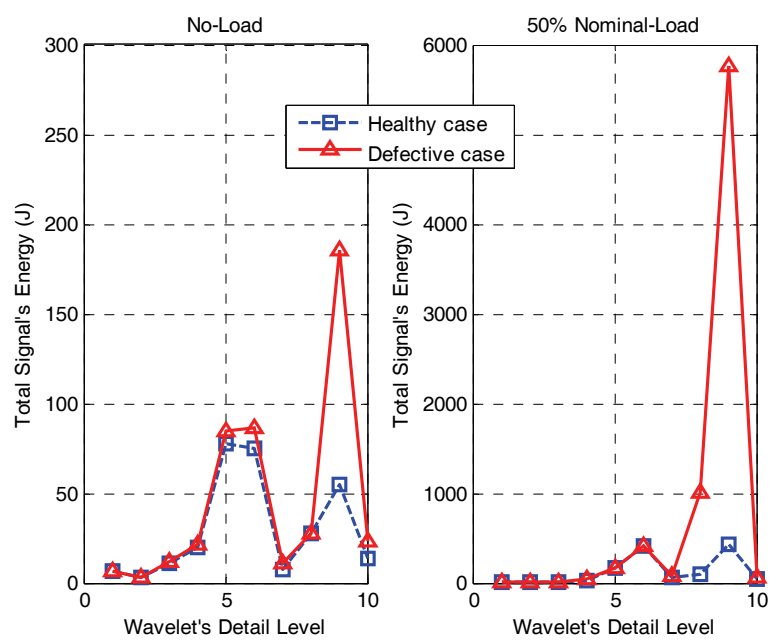

Fig. 16. Residual energy (corresponding to residual current) in healthy and faulty cases at no load and with a $50 \%$ nominal load

From this experiment, it is observed that the residual energy consumption in the faulty case is greater than in the healthy case, especially at the $9^{\text {th }}$ detail level.

Indeed, the speed value measured by the tachometer is $1467 \mathrm{rpm}$, so the slip value is $s=2.2 \%$ and the defect frequencies, given by (6) are $47.8 \mathrm{~Hz}$ and $52.2 \mathrm{~Hz}$. These values are respectively contained in the $9^{\text {th }}(50-25 \mathrm{~Hz})$ and $8^{\text {th }}(100-50 \mathrm{~Hz})$ detail levels. Therefore, the residual energy allows an easy distinction between the healthy and defective cases.

In order to emphasize the fault effect, a ratio $k$ will be computed as:

$$
k=\frac{E_{j}(\text { Faulty })-E_{j}(\text { Healthy })}{E_{j}(\text { Healthy })}
$$

Table 4 below shows the computed $k$ factor values at different detail levels, for both total and residual energies.

Table 4. Ratio " $k$ ” values at different decomposition levels

\begin{tabular}{c|c|c|c|c}
\hline \multirow{2}{*}{ Level } & \multicolumn{4}{|c}{$k$ ratio values } \\
\cline { 2 - 5 } & \multicolumn{2}{|c|}{ No-loaded motor } & \multicolumn{2}{c}{ Motor with a 50\% nominal load } \\
\cline { 2 - 5 } & $\begin{array}{c}\text { Total } \\
\text { Energy }\end{array}$ & $\begin{array}{c}\text { Residual } \\
\text { Energy }\end{array}$ & $\begin{array}{c}\text { Total } \\
\text { Energy }\end{array}$ & $\begin{array}{c}\text { Residual } \\
\text { Energy }\end{array}$ \\
\hline $\mathrm{d} 1$ & $0.00 \%$ & $2.80 \%$ & $0.00 \%$ & $30.1 \%$ \\
\hline $\mathrm{d} 2$ & $0.00 \%$ & $9.50 \%$ & $0.00 \%$ & $53.9 \%$ \\
\hline $\mathrm{d} 3$ & $0.00 \%$ & $7.70 \%$ & $0.00 \%$ & $56.0 \%$ \\
\hline $\mathrm{d} 4$ & $50.0 \%$ & $5.80 \%$ & $0.00 \%$ & $34.6 \%$ \\
\hline $\mathrm{d} 5$ & $-15.0 \%$ & $9.60 \%$ & $3.40 \%$ & $3.00 \%$ \\
\hline $\mathrm{d} 6$ & $5.20 \%$ & $15.4 \%$ & $1.40 \%$ & $0.70 \%$ \\
\hline $\mathrm{d} 7$ & $19.50 \%$ & $46.0 \%$ & $2.90 \%$ & $15.70 \%$ \\
\hline $\mathrm{d} 8$ & $-7.20 \%$ & $2.20 \%$ & $1.60 \%$ & $862.7 \%$ \\
\hline $\mathrm{d} 9$ & $44.70 \%$ & $235.5 \%$ & $3.50 \%$ & $1241 \%$ \\
\hline $\mathrm{d} 10$ & $-10.4 \%$ & $68.4 \%$ & $1.30 \%$ & $37.10 \%$ \\
\hline
\end{tabular}

The $k$ ratio value for the residual energy at the $9^{\text {th }}$ detail level is much higher than the other values which confirm 
the previous findings $(235.5 \%$ at no load and $1241 \%$ at half nominal load).

\section{Conclusion}

This paper dealt with the induction motor rotor faults detection. A new stator current-based fault detection approach is suggested. Indeed, it has been proposed to monitor induction motor rotor by means of the DWT of the residual current, obtained by subtraction between the stator current and its TSA. It was then found that the 9th detail level is the more energized level when a rotor fault occurs. The achieved results clearly demonstrate that the 9th detail levels of the residual current can be used as an effective indicator for rotor condition monitoring. The obtained results seem very promising for induction motor monitoring, since the approach is relatively simple. However, further investigations must be done toward the generalization of this approach to other types of faults which will be very beneficial for many industrial applications, including wind turbine monitoring.

\section{Nomenclature}

$\begin{array}{ll}a_{n} & \text { Approximation signal at level } \mathrm{n} \\ d_{j} & \text { Detail signal at level } \mathrm{j} \\ E_{j} & \text { Detail energy at level } j \\ f_{\text {defect }} & \text { Rotor-fault frequency } \\ f_{s} & \text { Supply frequency }(50 \mathrm{~Hz} \text { in this paper }) \\ f_{\text {samp }} & \text { Sampling rate }(25.6 \mathrm{kHz} \text { in this paper }) \\ I_{\text {res }}(t) & \text { Residual current } \\ I_{s}(t) & \text { Stator current } \\ <I_{s}(t)>_{\text {Th }} & \text { Synchronous averaged current at } T_{h} \text { period } \\ I_{\text {sh }}(t) & \text { Stator-current harmonic component } \\ I_{\text {smec }}(t) & \text { Mechanical-structure-related stator current } \\ N & \text { Total number of samples } \\ N_{\text {samp }} & \text { Number of samples per period } \\ S & \text { Per unit slip } \\ T_{h} & \text { Harmonic period }\left(T_{h}=1 / f_{s}\right)\end{array}$

\section{References}

[1] A. H. Bonnett, G. C. Soukup, "Cause and analysis of stator and rotor failures in three-phase squirrel-cage induction motors," IEEE Transactions on Industry Applications, vol. 28, no. 4, pp. 921-937, Jul.-Aug. 1992.

[2] S. Nandi, H. A. Toliyat, X. Li, "Condition monitoring and fault diagnosis of electrical motors - a review," IEEE Transactions on Energy Conversion, vol. 20, no. 4, pp. 719-729, Dec. 2005.

[3] D. G. Dorrell, W.T. Thomson, S. Roach, "Analysis of air-gap flux, current, and vibration signals as a function of the combination of static and dynamic air-gap eccentricity in 3-phase induction motors," IEEE Transactions on Industry Applications, vol. 33, no. 1, pp. 24-34, Jan.-Feb. 1997.

[4] C. J. Dister and R. Schiferl, "Using temperature, voltage, and/or speed measurements to improve trending of induction motors RMS currents in process control and diagnostics," in Proc. IAS Annual Meeting, 1998, pp. 312-318.

[5] T. A. Lipo, K. C. Chang, "A new approach to flux and torque-sensing in induction machines," IEEE Transactions on Industry Applications, vol. IA-12, no. 4, pp. 142-148, Jul.-Aug. 1986.

[6] R. R. Schoen, T. G. Habetler, F. Kamran, R. G. Bartfield, "Motor bearing damage detection using stator current monitoring," IEEE Transactions on Industry Applications, vol. 31, no. 6, pp. 1274-1279, Dec. 1995.

[7] S.H. Kia, H. Henao, G. Capolino, "Efficient digital signal processing techniques for induction machines fault diagnosis," in Proc. WEMDCD, 2013, pp. 232246.

[8] M.E.H. Benbouzid, "A review of induction motors signature analysis as a medium for faults detection," IEEE Transactions on Industrial Electronics, vol. 47, no. 5, pp. 984-993, Oct. 2000.

[9] I. Jaksch, P. Fuchs, "Rotor cage faults detection in induction motors by motor current demodulation analysis," in Proc. SDEMPED'07, 2007, pp. 247-252.

[10] Y. Gritli, L. Zarri, C. Rossi, F. Filippetti, G. A. Capolino, D. Casadei, "Advanced diagnosis of electrical faults in wound rotor induction machines," IEEE Transactions on Industrial Electronics, vol. 60, no. 9, pp. 4012-4024, Sep. 2013.

[11] Y.H. Kim, Y.W. Youn, D.H. Hwang, J.H. Sun, D.S. Kang, "High-resolution parameter estimation method to identify broken rotor bar faults in induction motors," IEEE Transactions on Industrial Electronics, vol. 60, no. 9, pp. 4103-4117, Sep. 2013.

[12] K.S. Gaeid, H.W. Ping, M.K. Masood, L. Szabo, "Survey of wavelet fault diagnosis and tolerant of induction machines with case study," International Review of Electrical Engineering, vol. 7, no. 3, pp. 4437-4456, Jun. 2012.

[13] M. Drif, A.J. Marques-Cardoso, "Discriminating the simultaneous occurrence of three-phase induction motor rotor faults and mechanical load oscillations by the instantaneous active and reactive power media signature analysis," IEEE Transactions on Industrial Electronics, vol. 59, no. 3, pp. 1630-1639, Mar. 2012.

[14] H. Keskes, A. Braham, Z. Lachiri, "Broken rotor bar diagnosis in induction machines through stationary wavelet packet transform and multiclass wavelet SVM," Electric Power Systems Research, Elsevier, vol. 97, pp. 151-157, Apr. 2013. 
[15] A. Garcia-Perez, R.J. Romero-Troncoso, E. CabalYepez, R.A. Osornio-Rios, "The application of highresolution spectral-analysis for identifying multiple combined faults in induction motors," IEEE Transactions on Industrial Electronics, vol. 58, no. 5, pp. 2002-2010, May 2011.

[16] S.H. Kia, H. Henao, G.A. Capolino, "Diagnosis of Broken-Bar Fault in Induction Machines Using Discrete Wavelet Transform Without Slip Estimation," IEEE Transactions on Industry Applications, vol. 45, no. 4, pp. 1395-1404, Jul.-Aug. 2009.

[17] J.T. Bialasiewicz, D. Gonzalez, J. Balcells, J. Gago, "Wavelet-Based Approach to Evaluation of Signal Integrity," IEEE Transactions on Industrial Electronics, vol. 60, no. 10, pp. 4590-4598, Oct 2013.

[18] H. Keskes, A. Braham, Z. Lachiri, "Diagnosis of broken rotor bar in induction machines using pitch synchronous wavelet transform," in Proc. POWERENG, 2013, pp. 896-901.

[19] F. Filippetti, D. Casadei, G.A. Capolino, "Condition monitoring and diagnosis of rotor faults in induction machines: State of art and future perspectives, in Proc. IEEE WEMDCD, 2013, pp. 196-209.

[20] M. A. Samonig, P. Nussbaumer, G. Stojicic, T. M. Wolbank, "Analysis of rotor fault detection in inverter fed induction machines at no load by means of finite element method," in Proc. IECON, 2011, pp. 17581763.

[21] W.R. Bennett, "Statistics of regenerative digital transmission," Bell System Technical Journal, vol. 37, no. 6, pp. 1501-1542, Nov. 1958.

[22] W.A. Gardner, C.M. Spooner, Cyclostationary signal processing, C.T. Leondes, Academic Press, 1994, pp. 1-92.

[23] F. Bonnardot, R. Boustany, A. Ibrahim, K. Sabri, J. Antoni, and M. El Badaoui, "Don't ignore nonstationarity: use it to advantage," presented at International Conference on Noise and Vibration Engineering, Leuven, Belgium, Sep. 18, 2006.

[24] P.D. McFadden, "A Revised Model for the Extraction of Periodic Waveforms by Time Domain Averaging," Mechanical Systems and Signal Processing, vol. 1, no. 1, pp. 83-95, Jan. 1987.

[25] N. Ngote, S. Guedira, M. Ouassaid, M. Cherkaoui, M. Maaroufi, "On the Monitoring of Rotor Fault in Induction Machine by the use of the TSA Method Applied to Stator Current," International Review of Electrical Engineering, vol. 7, no. 4, pp. 4822-4828, Aug. 2012.

[26] N. Ngote, S. Guedira, M. Cherkaoui, M. Ouassaid, “A New Hybrid "Park's Vector - Time Synchronous Averaging" Approach to the Induction Motor-fault Monitoring and Diagnosis," Journal of Electrical Engineering \& Technology, vol.9, no. 2, pp. 559-568, Mar. 2014.

[27] C. S. Burrus, Introduction to Wavelets and Wavelet
Transforms. A Primer. Englewood Cliffs, NJ: PrenticeHall, 1998.

[28] A. Ceban, R. Pusca, R. Romary, "Study of Rotor Faults in Induction Motors Using External Magnetic Field Analysis," IEEE Transactions on Industrial Electronics, vol. 59, no. 5, pp. 2082-2093, May 2012.

[29] R. Fiser, S. Ferkolj, "Modelling of dynamic performance of induction machine with rotor faults," in Proc. ICEM'96, 1996, pp. 17-22.

[30] L. Zarri, M. Mengoni, Y. Gritli, A. Tani, F. Filippetti, G. Serra, D. Casadei, "Detection and Localization of Stator Resistance Dissymmetry Based on Multiple Reference Frame Controllers in Multiphase Induction Motor Drives," IEEE Transactions on Industrial Electronics, vol. 60, no. 8, pp. 3506-3518, Aug 2013.

[31] A. Lebaroud, G. Clerc, "Study of Rotor Asymmetry Effects of an Induction Machine by Finite Element Method," Journal of Electrical Engineering \& Technology, vol. 6, no. 3, pp. 342-349, May 2011.

[32] P. Shi, Z. Chen, Y. Vagapov, Z. Zouaoui, “Optimal Wavelets for Broken Rotor Bars Fault Diagnosis," in Proc. SDEMPED, 2013, pp. 49-56.

[33] K.L.V. Iyer, X. Lu, Y. Usama, V. Ramakrishnan, N.C. Kar, "A Twofold Daubechies-Wavelet-Based Module for Fault Detection and Voltage Regulation in SEIGs for Distributed Wind Power Generation," IEEE Transactions on Industrial Electronics, vol. 60, no. 4, pp. 1638-1651, Apr 2013.

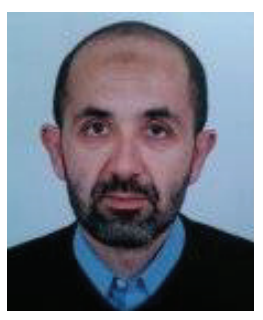

Nabil NGOTE was born in Casablanca, Morocco, in 1968. He received the diploma of "Ingénieur d'Etat" degree from the Ecole Nationale de l'Industrie Minérale, Rabat, Morocco, in 1990, in Electromechanical Engineering. He received Ph.D. degree, in Electrical Engineering from Ecole Mohammadia d'Ingénieurs, Université Mohamed V, Rabat, Morocco, in 2014. He is currently a Professor at "Ecole Nationale Supérieure des Mines de Rabat", Rabat, Morocco. His research interests are monitoring of electrical drives condition operation.

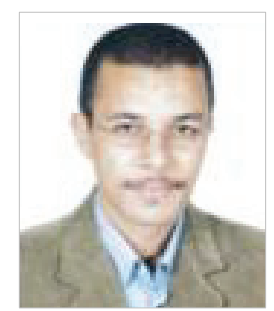

Mohammed Ouassaid was born in Rabat, Morocco, in 1970. He received the M.Sc.A. and Ph.D. degrees, in Electrical Engineering from Ecole Mohammadia d'Ingénieurs, Rabat, Morocco, in 2002 and 2006, respectively. He is currently a Professor at Ecole Mohammadia d'Ingénieurs,

Rabat, Morocco. His research interests are electric drives, power electronics, power systems and renewable energy. 


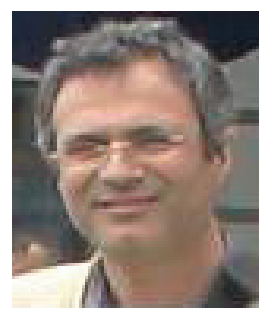

Saïd Guedira was born in Rabat, Morocco, in 1960. He received the diploma of "Ingénieur d'Etat" degree from the Ecole Mohammedia d'Ingénieurs, Rabat, Morocco, in 1983, and the Ph.D. degree from the Faculté Polytechnique de Mons, Belgium, in 1995, in Electrical Engineering. He is currently a Professor at "Ecole Nationale Supérieure des Mines de Rabat", Rabat, Morocco. His research interests include electrical network and predictive maintenance of rotating machines.

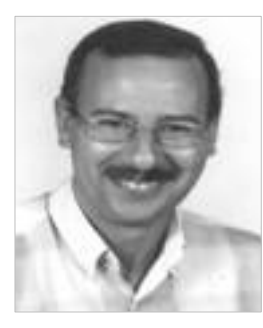

Mohamed Cherkaoui was born in Marrakech, Morocco, in 1954. He received the diplôme d'ingénieur d'état degree from the Ecole Mohammadia, Rabat, Morocco, in 1979 and the M.Sc.A. and Ph.D. degrees from the Institut National Polytechnique de la Loraine, Nancy, France, in 1983 and 1990, respectively, all in Electrical Engineering. In 1995, he joined the Department of Electrical Engineering, Ecole Mohammadia d'Ingénieurs, Rabat, Morocco, where is currently a Professor and University Research Professor. His current research interests include renewable energy, motor drives and power system. 